ANNALS OF “DUNAREA DE JOS” UNIVERSITY OF GALATI

MATHEMATICS, PHYSICS, THEORETICAL MECHANICS

FASCICLE II, YEAR XIII (XLIV) 2021, No. 1

DOI: https://doi.org/10.35219/ann-ugal-math-phys-mec.2021.1.07

\title{
2C-x and DOx hallucinogens: a systematic review
}

\author{
Iulia-Florentina Darie ${ }^{1}$, Mirela Praisler ${ }^{1 *}$, Catalin Negoita ${ }^{1}$ \\ 1 "Dunărea de Jos" University of Galati, Faculty of Science and Environment, 47 Domnească Street, \\ RO-800008, Galati, Romania \\ *Corresponding author: Mirela.Praisler@ugal.ro
}

\begin{abstract}
The drug market has seen a significant global expansion in the last decades. The synthetic designer drugs belonging to the class of amphetamines and derived phenylethylamines have experienced the greatest spread in the drug market for abuse. As phenylethylamines are organic compounds that stimulate the central nervous system of humans, many are abused as recreational drugs. A large array of substituted amphetamines can be easily synthetized by replacing one or more hydrogen atoms in the structure of phenylethylamine. Among these, the most dangerous for human health are those analogues or homologues that have hallucinogenic effects (besides the stimulant pharmacological activity), such as those belonging to the $2 \mathrm{C}$-x and DOx classes of amphetamines. This review describes the physico-chemical and spectral properties of the most representative compounds of the two classes.
\end{abstract}

Keywords: hallucinogenic amphetamines, synthetic drugs, 2C-x , DOx.

\section{INTRODUCTION}

Phenethylamines are monoamine alkaloids known for their stimulant effects on the human brain. Many of these compounds have limited or no medical use, due to their toxicity and user propensity to develop addiction and tolerance. However, over the past decades, many such synthetic drugs have increasingly been sold on the black market, in various forms.

These "designer drugs" are produced by clandestine laboratories as alternatives for existing scheduled drugs [1]. In order to avoid the legal consequences of selling controlled substances, they are constantly supplying the illicit market with new phenethylamines, which are generally obtained by performing small chemical alterations of the parent compound (by substituting one or more hydrogen atoms in the phenethylamine structure) that do not change significantly its psychotropic effects.

Two important classes of novel phenylethylamines are $2 \mathrm{C}-\mathrm{x}$ and DOx. This paper presents a synthesis of the main proprieties of the most representative compounds from each class.

\section{EXPERIMENTAL}

The types of compounds with psychedelic and hallucinogenic effects fall into different categories, having similar effects but different times of reaction and effects on the human body. $2 \mathrm{C}$ $(\mathbf{2 C}-\mathbf{x})$ is the generic name given to the group of psychedelic phenethylamines that contain methoxy groups on the 2 and 5 positions of a benzene ring [2]. Most of these substances have in their composition lipophilic substituents at the 4 position, which makes them more stable from a metabolical point of view, with a longer-lasting and stronger pharmacological effect [3].

The first experiments on the chemical composition of known hallucinogens, which have led to the synthesis of the majority of the $2 \mathrm{C}$ compounds that are familiar to scientists nowadays, have been conducted by Alexander Shulgin, in the 1970s and 1980s. The results of his work were published in his book PiHKAL (Phenethylamines I Have Known And Loved), which introduced the term 2C which stands for the two carbon atoms present between the amino group and the benzene ring [4].

Some of these $2 \mathrm{C}$-x compounds appeared on the worldwide illicit market for psychoactive 
drugs at the beginning of the $21^{\text {st }}$ century [5]. Part of these substances were categorised as risk substances since they were first discovered and were allotted to one of the known risk groups. Other $2 \mathrm{C}$-x compounds took a longer time to be qualified as such [6]. Different studies, which indicated that these substances are dangerous and addictive, led to the inclusion of 2Cs in Schedule 1 type of drugs, at various times, in most of the countries. For example, in the United States, 2C-x substances such as 2C-E were scheduled in 2012, while others, such as 2C-B, were introduced as early as the 1990s. The European Council has instituted control measures and criminal charges for the consumption and distribution of 2C-I in 2003, whereas in the USA this happened only in 2012. This classification is done based on their approved (or not) medical use, side effects, and their potential to create addiction [7].

The 2C-x drugs are marketed in powder or pill form, which means that they can be either ingested or inhaled $[6,8]$. They may generate physiological responses of the $5-H T_{2 A}$ and alpha adrenergic receptors, but may also have antagonistic effects. As they may not be used in legal pharmaceutical preparations, the effects of the $2 \mathrm{C}$-x compounds on human beings have not been extensively analyzed or documented scientifically. However, they are known to induce hallucinogenic effects of various intensity. For example, in low doses, 2C-x compounds may stimulate receptors, making the sensorial perception more potent or acute. In high doses, these substances may be extremely dangerous, causing hallucinations, high blood pressure, tachycardia, convulsions, and even death $[6,9]$.

2C-B (also known as Nexus, Venus, Bees, Bromo Mescaline or Pink Cocaine) is a synthetic drug that was first sold as an aphrodisiac [10] and then abused for its hallucinogenic effects [11]. First synthetized by Shulgin in 1974, it became popular a few years later as an alternative for MDMA [12]. During the last decade, it has become common practice for drug abusers to combine 2C-B with MDMA [13]. The presence of 2C-B in the MDMA tablets is most probably a way to avoid legal consequences [14]. However, this practice may increase the harmful potential of the dose [15]. Used in quantities varying between 12 and $24 \mathrm{mg}, 2 \mathrm{C}-\mathrm{B}$ is reported, in Shulgin's PiHKAL, to induce psychotropic effects lasting 4 to 8 hours [4]. Other reports indicate that the effects of a dose of 10 to $40 \mathrm{mg}$, administered in powder or pill form, may last 4 to 6 hours when ingested [16, 10]. The Erowid Website's users report pupil dilation, mental stimulation, anxiety, closed-eye visuals, or even openeyed visual patterning at high doses of 2C-B [10].

2C-C is a psychedelic drug with a short-acting duration [17]. Shulgin indicates in PiHKAL that dosage from 20 to $40 \mathrm{mg}$ of $2 \mathrm{C}-\mathrm{C}$ generates psychotropic effects lasting 4 to 8 hours. As the main effects, he mentioned a relaxed mood and a large number of visuals at high doses [4, 18]. According to a study conducted in 2013, 2C-C, as well as 2C-B and 2C-I, have been detected on the Taiwanese illicit drug market between 1999 and 2011 [19].

2C-E (also known as Europa [20]) is a psychedelic phenethylamine similar in structure to mescaline. It was first synthetized by Shulgin in 1977. An observational study about its effects on humans reports hallucinations or altered perceptions as the main effects [21]. According to PiHKAL, when consumed in doses of 10 to $25 \mathrm{mg}$, the effects of 2C-E last between 8 to 12 hours [4]. Other reports indicate effects that may endure for 5 to 9 hours for a dosage of 5 to $30 \mathrm{mg}$. The main reported effects are pupil dilation, tension, anxiety, an increase in heart rate, nausea, or paranoia.

DOx (4-Substituted-2,5-dimethoxyamphetamines) is a class of substituted amphetamines containing methoxy groups at the 2- and 5- positions of their aromatic ring, and a substituent, for example, alkyl or halogen, at the 4- position of the phenyl ring [3, 22]. First synthetized by Shulgin, the DOx amphetamines are psychedelic drugs that have a lasting effect and act as partially selective agonists of the $5-H T_{2 A}, 5-H T_{2 B}, 5-H T_{2 C}$ receptors. The first compound synthetized by Shulgin (in 1964) was 2,5-Dimethoxy-4-methylamphetamine (DOM). Analogs such as 2,5-Dimetoxy4-bromamphetamine (DOB), 2,5-Dimetoxy-4-cloramphetamine (DOC), 2,5-Dimetoxy-4iodamphetamine (DOI) and 1-(4-Bromofuro[2,3-f][1] benzofuran-8-yl) propan-2-amine (BromoDragonFLY) followed shortly after. Although some DOx compounds have been noticed on the illegal drug market for a few decades, they became extremely popular among users only in the $21^{\text {st }}$ century [6]. 
Research done on rodents, highlighting the pharmacological activity of DOx compounds in comparison with other types of amphetamines, indicates that the effects of DOx drugs are similar to those of natural hallucinogens such as mescaline or LSD [23, 24]. The administration of DOx substances may have a negative influence on human health: especially in large doses, they may seriously affect the cardiovascular system [6].

DOB (also known as Brolamfetamine) is a synthetic DOx drug with psychedelic effects that was synthetized by Shulgin in 1967. The first published reference dates from 1971 [25]. DOB has become popular for its long-lasting effects at very high doses. Its effects are similar to its homologue, $2 \mathrm{C}-\mathrm{B}$, but last a longer period of time [26]. On the other hand, as the DOB effects do not show immediately, the danger of an overdose is very high for those who re-ingest the substance.

User's reports indicate effects such as increased energy, color shift, mental clarity (even in low doses), visual effects, tense jaw, nausea, general body discomfort in medium doses, and visual brightening or exulting happiness in high doses [26, 27]. Redosing one hour after the first dose may lead to an overdose, experiencing effects such as violent or irrational behavior and memory loss.

For DOB, PiHKAL indicates a dosage from 1 to $3 \mathrm{mg}$, the effects lasting from 18 up to 30 hours [4]. However, later reports indicate that different doses have different time effects. For example, the effects of DOB can last from 6 to 24 hours, depending on the dose varying between 0.2 and $3.5 \mathrm{mg}$ [26]. A study indicates the possibility of this substance to cause fluctuation in the levels of serotonin and dopamine [28].

An analysis done in the Netherlands by the Drug Information Monitoring System shows the presence of DOB in Ecstasy tablets [29]. The presence of DOB was also revealed in samples sold as DOC or LSD on the Spanish market [30].

DOM (also known as STP - "Serenity, Tranquility, and Peace") became very popular in the late 1960s. It induces effects similar to mescaline, but one hundred times stronger. It can also be compared with LSD but outdoing its potential effects [31,32]. A study on the biological activity of DOM on humans has shown that doses outrunning $5 \mathrm{mg}$ produce psychotomimetic effects such as hallucinations, sound patterns or accentuated sensory perceptions [33]. For DOM, Shulgin indicated the duration of the effects from 14 to 20 hours for a dosage between 3 and $10 \mathrm{mg}$ [4, 34].

DOI is a psychedelic drug with little recreational use, but which is frequently used in research. Like DOB, it produces full effects with only a small dose [35]. Studies have proved that DOI may act as a serotonin receptor agonist [36], but also as a potent anti-inflammatory [37]. DOI seems to be used in doses varying between 1.5 and $3 \mathrm{mg}$, with an effect duration from 16 to 30 hours [35].

\section{RESULTS AND DISCUSSIONS}

The literature in the field details specific methods and procedures that may be employed to identify the presence of $2 \mathrm{C}$-x and DOx substances in samples taken from all types of sources. Harper et al. have provided a summary of the methods and technologies used in drug detection, as agreed on by the Scientific Working Group for the Analysis of Seized Drugs (SWGDRUG). These methods can be classified, according to the identification accuracy, into two categories: very discriminatory and less discriminatory. The less discriminatory methods only provide a presumptive identification of the drug, without quantifying it. This kind of method is usually followed by a very discriminatory method, in order to offer a precise identification and even a quantification of the drug.

The most discriminatory methods for the identification of 2C-x and DOx hallucinogens include Mass Spectrometry (MS), Fourier Transform Infrared Spectrometry (FTIR), Raman Spectroscopy (RS), and X-ray diffractometry. Less discriminatory methods are Thin-layer chromatography (TLC), Ultraviolet spectroscopy (UVS), Spot/color tests, Microcrystalline tests, Immunoassay, and Urine dipstick tests [38].

There are different ways of detecting hallucinogenic amphetamines. In 2011, Kerrigan et al. have used Gas Chromatography (GC) to identify 2C-x and DOx drugs in urine, by using selected ion monitoring [39]. Three years later, Kerrigan et al. (2014) reported the results obtained with Liquid Chromatography - tandem Mass Spectrometry (LC-MS/MS) for the detection of fifteen 2C-x and DOx compounds in urine samples [40]. Immunoassays are also used to identify a particular type of substance, depending on the nature or concentration of the drug. 
However, some substances may not be detected with these methods, which shows their limitations and the need for more specific analytical tools. Nowadays, GC-MS, LC-MS, or GC-FTIR are among the most efficient methods used for detecting drugs of abuse [41]. Pichini et al resorted to LC-MS and spay ionization to screen for and quantify drugs of abuse such as $2 \mathrm{C}-\mathrm{B}, 2 \mathrm{C}-\mathrm{D}, 2 \mathrm{C}-\mathrm{E}, 2 \mathrm{C}-\mathrm{I}$, 2C-T-2, or 2C-B-Fly [42].

Another group of scientists, led by Helena K Nordgren, has successfully used a combination of LC-MS/MS and atmospheric pressure chemical ionization (APCI) [43] for the detection of a multitude of drugs, including 2C-B, DOB, DOI and 2,5-DMA.

In 2005, Habrdova and collaborators have used GC-MS to screen and quantify in blood plasma a number of seven $2 \mathrm{C}$ compounds, i.e. 2C-D, 2C-E, 2C-P, 2C-B, 2C-I, 2C-T-2 and 2C-T-7, obtaining full validation [44].

As $2 \mathrm{C}-\mathrm{B}$ is among the most frequently used $2 \mathrm{C}$ drug of abuse, many analytical methods were developed in order to determine its presence in samples collected from biological sources or seized materials. Nuclear magnetic resonance (NMR), UVS and MS data regarding the detection of 2C-B were presented by Ragan and collaborators. Giroud and collaborators have identified 2C-B in seized materials by using FTIR, GC-MS, High-Performance Liquid Chromatography (HPLC)-diode array detection (DAD), NMR, and Capillary Electrophoresis (CE) - DAD [45 - 47].

The data obtained with the above mentioned methods have been often processed by applying multivariate (artificial intelligence) methods, in order to improve the quality of the illicit amphetamines detection. Studies in the field have revealed a significant improvement in the efficiency in detecting synthetic drugs when multivariate methods such as Principal Component Analysis (PCA) $[48,49]$ or Soft Independent Modeling of Class Analogy (SIMCA) [50, 51] have been used.

The other two pattern recognition methods, i.e. Hierarchical Cluster Analysis (HCA) and the Naive Bayes Classifier (NBC) have been successfully used in order to detect amphetamines based on their GC-IR spectra. The results revealed how useful HCA is for this purpose, and how much the Naïve Bayes Classifier (NBC) may improve the drug classification accuracy [52].

A significant improvement in the detection of hallucinogenic amphetamines based on their ATR-FTIR spectra may also be obtained by using the Genetic (evolutionary) Algorithm (GA) for selecting the most relevant spectroscopic data [53].

In 2019, Ciochina et al have reported a chemometric application developed to automatize the processing of the GC-IR spectral data obtained with a portable infrared sensor designed to detect illicit phenethylamines, highlighting the remarkable results obtained with PCA [54]. Other pattern recognition systems, using HCA and Naive Bayesian Classifier (NBC), have also been built to automatize and improve the efficiency in recognizing the class identity of amphetamines [55].

In 2020, Negoita et al provided an important approach to the detection of several compounds from the 2C-x and DOx classes based on their ATR-FTIR spectra [56].

\section{CONCLUSIONS}

As the illegal drug market is constantly providing new psychoactive substances, the need for more extensive studies about efficient ways of identification requires the development of new methods and techniques that may help identify and isolate drugs of abuse, especially the highly toxic ones, such as $2 \mathrm{C}-\mathrm{x}$ and DOx amphetamines.

\section{References}

1. Hill S. L., Thomas S. H. L., Clinical toxicology of newer recreational drugs, Clinical Toxicology 49 (2011) 705-719.

2. Shulgin A., Manning T., Daley P.F., The Shulgin Index. Volume 1, Psychedelic Phenethylamines and Related Compounds, Transform Press, 2011.

3. Trachsel D., Lehmann D., Enzensperger C., Phenethylamine Von der Struktur zur Funktion, Nachtschatten Verlag AG, pp. 762-810, 2013.

4. Shulgin A., Shulgin A., PiHKAL: A Chemical Love Story, Transform Press California, 1991. 
5. de Boer D., Bosman I., A new trend in drugs-of-abuse; the 2C-series of phenethylamine designer drugs, Pharmacy World and Science 26 (2004) 110-113.

6. Herrmann E. S., Johnson P.S. , Johnson M. W., Vandrey R., Novel Drugs of Abuse: Cannabinoids, Stimulants, and Hallucinogens, in: Neuropathology of Drug Addictions and Substance Misuse, (Preedy V. R., editor), Academic Press, pp. 893-902, 2016.

7. https://www.dea.gov/drug-scheduling

8. https://www.dancewizensw.org.au/2cx

9. Dean B. V., Stellpflug S. J., Burnett A. M., Engebretsen K. M., 2C or not 2C: phenethylamine designer drug review, Journal of Medical Toxicology 9 (2013) 172-178.

10. National Drug Intelligence Center. Department of Justice. 2C-B (Nexus) Reappears on the Club Drug Scene, May 2001.

11. https://erowid.org/chemicals/2cb/2cb.shtml

12. Shulgin A. T, Carter M. F., Centrally active phenethylamines, Psychopharmacology Communications 1 (1975) 93-98.

13. González D., Ventura M., Caudevilla F., Torrens M., Farre M., Consumption of new psychoactive substances in a Spanish sample of research chemical users, Human Psychopharmacology 28(4) (2013) 332-340.

14. Togni L.R., Lanaro R., Resende R.R., Costa J.L., The variability of ecstasy tablets composition in Brazil, Journal of Forensic Sciences 60 (2015) 147-151.

15. Giné C.V., Espinosa I..F, Vilamala M.V., New psychoactive substances as adulterants of controlled drugs, A worrying phenomenon?, Drug Testing and Analysis 6 (2014) 819-824.

16. https://psychonautwiki.org/wiki/2C-B

17. https://www.erowid.org/chemicals/2cc/2cc.shtml

18. https://erowid.org/library/books_online/pihkal/pihkal022.shtml

19. Lee S. F., Hsu J., Tsay W. I., The trend of drug abuse in Taiwan during the years 1999 to 2011, Journal of Food and Drug Analysis 21 (2013) 390-396.

20. Sutherland R., Peacock A., Whittaker E., Roxburgh A., Lenton S., Matthews A., Bruno R., New psychoactive substance use among regular psychostimulant users in Australia, 2010-2015, Drug and Alcohol Dependence 161 (2016) 110-118.

21. Papaseit E., Olesti E., Pérez-Mañá C., Torrens M., Grifell M., Ventura M., Pozo O.J., de Sousa Fernandes Perna E.B., Ramaekers J.G., de la Torre R., Farré M., Acute Effects of 2C-E in Humans: An Observational Study, Frontiers in Pharmacology 11 (2020) Article 233.

22. https://psychonautwiki.org/wiki/DOx

23. Glennon R. A., Young R., Jacyno J. M., Slusher M., Rosecrans J. A., DOM-stimulus generalization to LSD and other hallucinogenic indolealkylamines, European Journal of Pharmacology 86 (1983) 453-459.

24. Silverman P. B., Ho B. T, The discriminative stimulus properties of 2, 5-dimethoxy-4methylamphetamine (DOM): differentiation from amphetamine, Psychopharmacology 68 (1980) 209-215.

25. Shulgin A.T. Sargent T. Naranjo C., 4-Bromo-2,5-Dimethoxyphenylisopropylamine, a New Centrally Active Amphetamine Analog, Pharmacology 5 (1971) 103-107.

26. https://www.erowid.org/chemicals/dob/dob.shtml

27. https://psychonautwiki.org/wiki/DOB

28. Rusterholz D.B., Spratt J.L., Long J.P., Kelly T.F., Serotonergic and dopaminergic involvement in the mechanism of action of $R-(-)-2,5$-dimethoxy-4-bromoamphetamine (DOB) in cats, in: Life Sciences, 23(14), pp.1499-1506, 1978.

29. Vogels N., Brunt T.M., Rigter S., van Dijk P., Vervaeke H., Niesink R.J., Content of ecstasy in the Netherlands: 1993-2008, Addiction 104 (2009) 2057-2066.

30. Quintana-Mathé P., Grifell-Guardia M., Palma-Conesa Á., Gil-Lladanosa C., Fornís-Espinosa I., Caudevilla-Galligo F., Gallindo-Guarin L., Farre-Albaladeo M., Ventura-Vilamala M., Torrens-Melich M., Presence of 2,5-dimethoxy-4-bromoamphetamine (DOB) among samples brought for drug checking in Spain, in: European Psychiatry, 33(S), pp. S171, 2016.

31. https://www.erowid.org/chemicals/dom/dom.shtml 
32. Clarke Z., 2,5 Dimethoxy 4 Methylamphetamine, Editor(s): Enna S.J., Bylund D.B., in: xPharm: The Comprehensive Pharmacology Reference, Elsevier, pp. 1-3, 2007.

33. Hollister L.E., Macnicol M.F., Gillespie H.K., An hallucinogenic amphetamine analog (DOM) in man, Psychopharmacologia 14 (1969) 62-73.

34. https://erowid.org/library/books_online/pihkal/pihkal068.shtml

35. https://www.erowid.org/chemicals/doi/doi.shtml

36. Fantegrossi W.E., Simoneau J., Cohen M.S., Zimmerman S.M., Henson C.M., Rice K.C., Woods J.H., Interaction of 5-HT2A and 5-HT2C receptors in R(-)-2,5-dimethoxy-4iodoamphetamine-elicited head twitch behavior in mice, Journal of Pharmacology and Experimental Therapeutics 335 (2010) 728-734.

37. Yu B., Becnel J., Zerfaoui M., Rohatgi R., Boulares A. H., Nichols C. D., Serotonin 5Hydroxytryptamine(2A) Receptor Activation Suppresses Tumor Necrosis Factor- $\alpha$-Induced Inflammation with Extraordinary Potency, Journal of Pharmacology and Experimental Therapeutics 327 (2008) 316-323.

38. Harper L., Powell, J., Pijl E.M., An overview of forensic drug testing methods and their suitability for harm reduction point-of-care services., Harm Reduction Journal 14 (2017) 1-13.

39. Kerrigan S., Banuelos S., Perrella L., Hardy B., Simultaneous detection of ten psychedelic phenethylamines in urine by gas chromatography-mass spectrometry, Journal of Analytical Toxicology 35 (2011) 459-469.

40. Kerrigan S., Mott A., Jatzlau B., Ortiz F., Perrella L., Martin S., Bryand K., Designer psychostimulants in urine by liquid chromatography-tandem mass spectrometry, Journal of Forensic Sciences 59 (2014) 175-183.

41. Swortwood M. J., Hearn W. L., DeCaprio A. P., Cross-reactivity of designer drugs, including cathinone derivatives, in commercial enzyme-linked immunosorbent assays, Drug Testing and Analysis 6 (2014) 716-727.

42. Pichini S., Pujadas M., Marchei E., et al., Liquid chromatography-atmospheric pressure ionization electrospray mass spectrometry determination of 'hallucinogenic designer drugs' in urine of consumers, Journal of Pharmaceutical and Biomedical Analysis, 47 (2008) 335-342.

43. Nordgren H.K., Holmgren P., Liljeberg P. et al., Application of direct urine LC-MS-MS analysis for screening of novel substances in drug abusers, Journal of Analytical Toxicology 29 (2005) 234-239.

44. Habrdova V., Peters F.T., Theobald D.S. et al., Screening for and validated quantification of phenethylamine-type designer drugs and mescaline in human blood plasma by gas chromatography/mass spectrometry, Journal of Mass Spectrometry 40 (2005) 785-795.

45. Papoutsis, I., Nikolaou, P., Stefanidou, M. et al., 25B-NBOMe and its precursor 2C-B: modern trends and hidden dangers, Forensic Toxicology 33 (2015) 1-11.

46. Ragan F.A. Jr., Hite S.A., Samuels M.S., Garey R.E., 4-Bromo-2,5-dimethoxyphenethylamine: identification of a new street drug, Journal of Analytical Toxicology 2 (1985) 91-93.

47. Giroud C., Augsburger M., Rivier L., Mangin P., Sadeghipour F., Varesio E., Veuthey J.L., Kamalaprija P., 2C-B: a new psychoactive phenylethylamine recently discovered in Ecstasy tablets sold on the Swiss black market, Journal of Analytical Toxicology, 22 (1998) 345-354.

48. Praisler M., Dirinck I., Van Bocxlaer J., De Leenheer A, Massart D.L., Exploratory analysis for the automated identification of amphetamines from vapour-phase FTIR spectra, Analytica Chimica Acta 404 (2000) 303-317.

49. Praisler M., Van Bocxlaer J., De Leenheer A., Massart D.L., Automated recognition of ergogenic aids using Soft Independent Modeling of Class Analogy (SIMCA), Turkish Journal of Chemistry 26 (2002) 45-58.

50. Praisler M., Van Bocxlaer J., De Leenheer A., Massart D.L., Chemometric detection of thermally degraded samples in the analysis of drugs of abuse with GC-FTIR spectroscopy, Journal of Chromatography A 962 (2002) 161-173.

51. Praisler M., Dirinck I., Van Bocxlaer J., De Leenheer A., Massart D. L., Identification of novel illicit amphetamines from vapor-phase FTIR spectra - a chemometrical solution, Talanta 53 (2000) 155-170. 
52. Praisler M., Ciochină S., Comparative assessment of the modeling and discrimination power of two pattern recognition methods applied to detect designer drugs, Annals of Dunarea de Jos University of Galati, Fascicule II, 41 (2018) 76-84.

53. Negoita C., Praisler M., Evolutionary algorithm applied for improving the accuracy of the automated detection of psychedelic amphetamines, Annals of Dunarea de Jos University of Galati, Fascicule II, 41 (2018) 70-75.

54. Ciochină S., Praisler M., Chemometric application operating a portable laser infrared sensor detecting illicit phenethylamines, Annals of Dunarea de Jos University of Galati, Fascicule II, 42 (2019) 49-54.

55. Praisler M., Ciochină S., Pattern recognition analysis of the class identity recognition efficiency of a portable laser infrared sensor detecting amphetamines and their main precursors, Annals of Dunarea de Jos University of Galati, Fascicule II, 42 (2019) 55-62.

56. Negoita C., Praisler M., Improved detection of 2C-x and Dox amphetamines - an analytical tool mitigating the environmental impact of their illicit manufacturing, consumption and disposal, Annals of the Dunarea de Jos University of Galati, Fascicule II, 43 (2020) 134-140. 